\title{
THERAPY OF ENDOCRINE DISEASE
}

\section{Surgery in microprolactinomas: effectiveness and risks based on contemporary literature}

\author{
Metaxia Tampourlou ${ }^{1,2}$, Raluca Trifanescu ${ }^{3}$, Alessandro Paluzzi ${ }^{4}$, \\ Shahzada K Ahmed ${ }^{5}$ and Niki Karavitaki, ${ }^{1,2}$ \\ ${ }^{1}$ Institute of Metabolism and Systems Research, University of Birmingham, ${ }^{2}$ Centre for Endocrinology, \\ Diabetes and Metabolism, Birmingham Health Partners, Birmingham, UK, ${ }^{3}$ Department of Endocrinology, \\ Carol Davila University of Medicine and Pharmacy, Bucharest, Romania, ${ }^{4}$ Department of Neurosurgery \\ and ${ }^{5}$ Department of Otorhinolaryngology, University Hospitals Birmingham NHS Foundation Trust, \\ Queen Elizabeth Hospital, Birmingham, UK
}

\author{
Correspondence \\ should be addressed \\ to N Karavitaki \\ Email \\ n.karavitaki@bham.ac.uk
}

\begin{abstract}
Microprolactinomas are the most common pituitary adenomas. In symptomatic patients, dopamine agonists are the first-line treatment of choice; when cabergoline is used, biochemical control rates between 85 and $93 \%$ have been reported. Long-term treatment is needed in most of the cases with compliance, patient convenience, and potential adverse effects representing areas requiring attention. Based on the literature published in the past 15 years, transsphenoidal surgery can lead to normal prolactin in the postoperative period in usually $71-100 \%$ of the cases with very low postoperative complication rates. Surgical expertise is the major determinant of the outcomes, and it may be a cost-effective option in young patients with life expectancy greater than 10 years (provided it is performed by experienced surgeons at high volume centers with confirmed optimal outcomes). Larger series of patients with adequate follow-up could further validate the place of transsphenoidal surgery (particularly through the endoscopic approach for which long-term results are currently limited) in the management algorithm of patients with microprolactinoma.
\end{abstract}

\section{Introduction}

Prolactinomas are the most common pituitary adenomas accounting for $51-66 \%$ of these tumours; recent epidemiological studies have suggested the prevalence of 44-62 cases/100 000 population (1). The median age at diagnosis is 32 years, with $76-81 \%$ of them being microadenomas $(1,2)$. The clinical manifestations of microprolactinomas are attributed to prolactin (PRL) excess and include galactorrhea and those of hypogonadotropic hypogonadism. The main aims of their treatment include normalization of PRL and amelioration of the clinical consequences of the hyperprolactinemia, prevention of tumor growth, as well as improvement of the quality of life. The adoption of a treatment option with the highest success rate, less side effects/complications, and optimal

www.eje-online.org DOI: 10.1530/EJE-16-0087
() 2016 European Society of Endocrinology Printed in Great Britain cost-effectiveness is of major importance. Currently, dopamine agonists (DAs) are the first-line therapy for symptomatic microprolactinomas, and transsphenoidal surgery is recommended to symptomatic patients who cannot tolerate high doses of cabergoline or who are not responsive to DA therapy (3).

Resistance to DA includes a failure to achieve normal PRL on maximally tolerated doses of DA and a failure to achieve tumor shrinkage more than 50\% (4). The second criterion would be considered clinically important, mainly for macroprolactinomas due to their potential to exert pressure effects to surrounding structures. Decreased number of dopamine receptors 2 (D2) has been reported in DA-resistant prolactinomas, but the mechanism of DA resistance has

Published by Bioscientifica Ltd. 


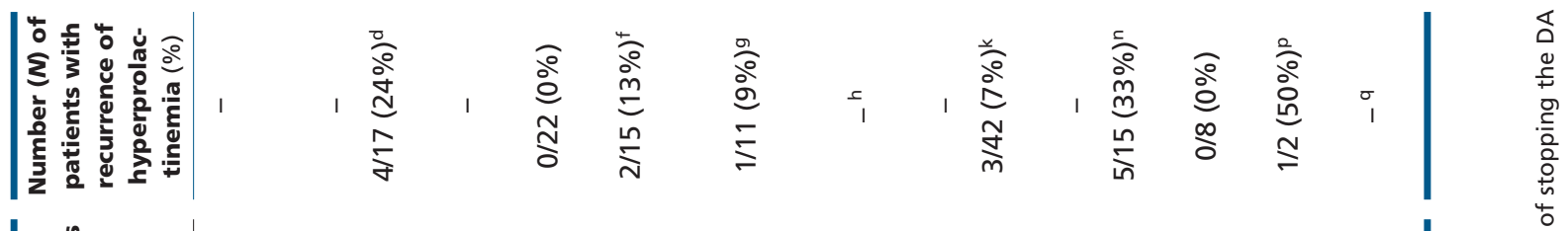

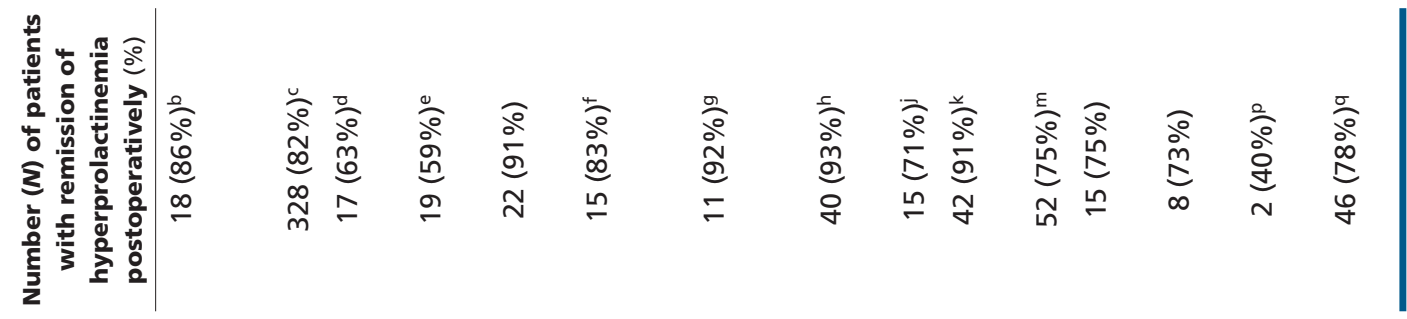

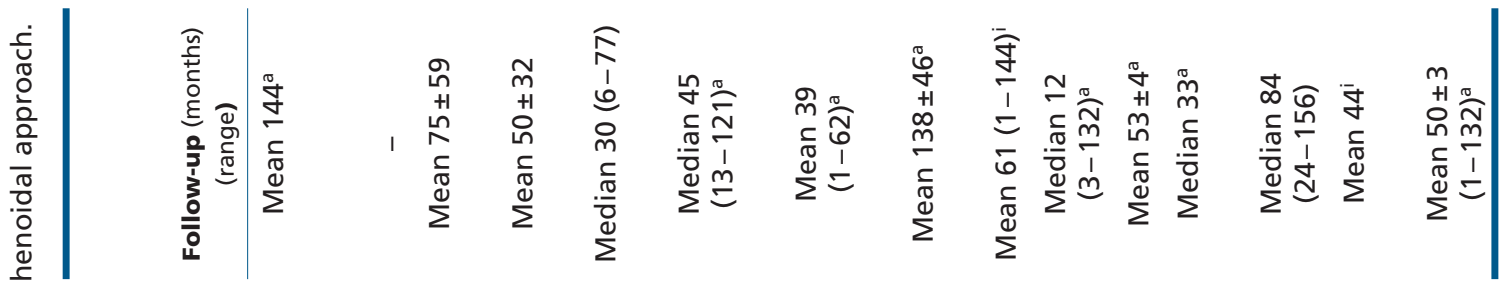
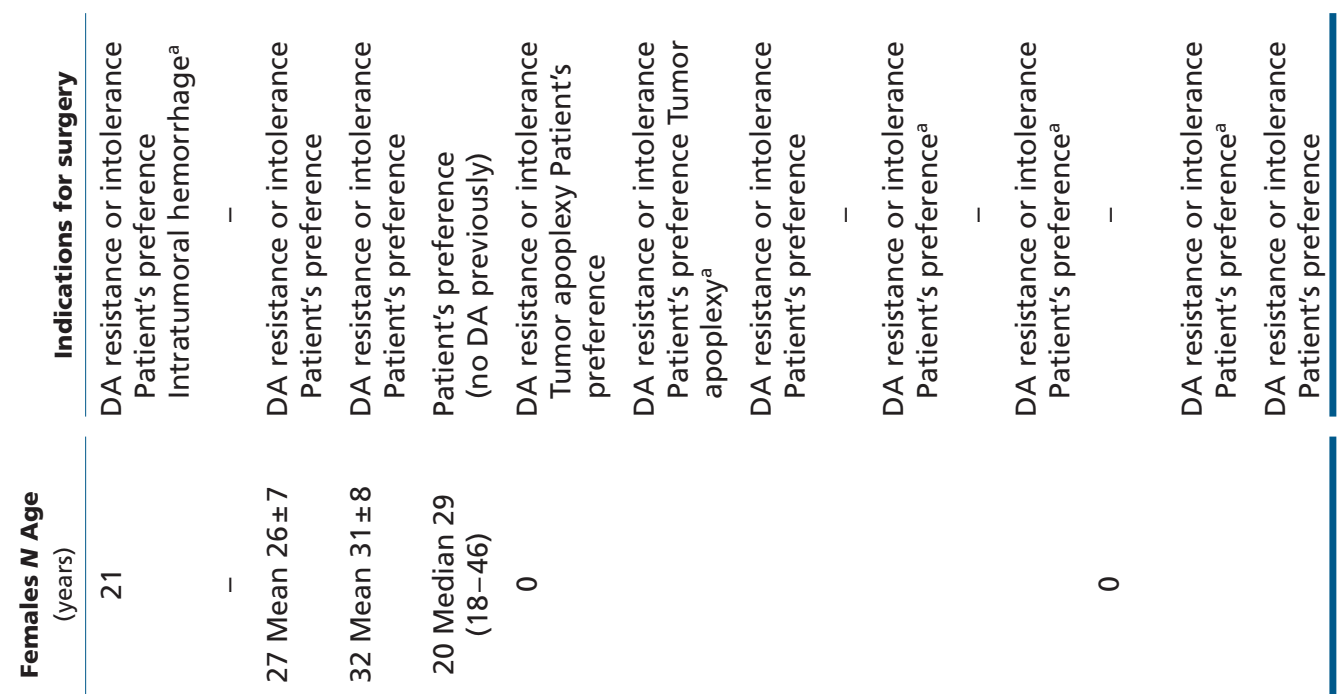

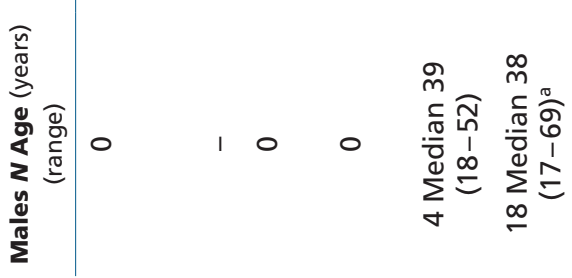


not been completely elucidated $(3,4)$. The prevalence of resistance to DA treatment differs between the various agonists and is less common in microprolactinomas and in women $(3,5,6)$. The reported rates of PRL normalization in patients with microprolactinomas are around 57\% with bromocriptine and 85 - 93\% with cabergoline $(5,6,7,8)$, with the latter agent leading to normoprolactinemia in a significant number of bromocriptine-resistant patients (4). A recent meta-analysis suggested that persisting normoprolactinemia after withdrawal of DA is expected in only $21 \%$ of the cases with the probability being higher when cabergoline had been used for at least 2 years, and pituitary MRI had shown normal appearances before DA discontinuation $(9,10)$. Side effects of these agents are mainly gastrointestinal with nausea and vomiting, as well as headaches and drowsiness; these can be minimized by gradual titration of the dose offered at bedtime. Mood alterations (anxiety and depression), psychosis, or behavioral changes, including impulse control disorders may also occur and are considered to be reversible when the medication is stopped $(4,11)$. Discontinuation of treatment due to intolerance has been described in $4 \%$ of the cases on cabergoline and $12 \%$ on bromocriptine $(6,7)$. Although a clinically concerning association between the use of DAs for the treatment of hyperprolactinemia and cardiac valvulopathy is not supported by the recently published literature (12), concerns remain on the impact of long-term use of cabergoline, even in low weekly doses, resulting in large cumulative doses.

A systematic review of the outcomes of surgery specifically in patients with microprolactinomas based on the contemporary published literature is not available. Given the advances in transsphenoidal surgical techniques, and especially the minimally invasive ones that have taken place in the past few years, such an analysis is of major importance and will facilitate therapeutic decisions relying on existing evidence. We have, therefore, reviewed the available literature on the surgical management of microprolactinomas (microscopic and endoscopic) published between 2000 and 2015, and we have extensively assessed the data on biochemical remission and recurrence rates, predictive factors of recurrence, perioperative complications, and cost implications.

\section{Transsphenoidal surgery for microprolactinomas}

Surgery for microprolactinomas is currently performed through the transsphenoidal route with a microscope, 
an endoscope, or both. The endoscopic endonasal approach-a minimally invasive technique offering superior panoramic view and the benefits of avoiding submucosal transseptal dissection (thereby eliminating nasoseptal perforations), as well as less patient discomfort due to the lack of nasal packing - has been applied in the latest years with less available published literature.

\section{Remission and recurrence rates after transsphenoidal surgery}

A summary of the surgical success rates from 45 studies published between 1977 and 2005 (84.4\% of them before 2000) showed high variability in the achievement of normal PRL (38-100\%), possibly reflecting differences in the neurosurgical expertise; the remission rate, as estimated based on the total number of included patients, was $74.7 \%$ and the recurrence of hyperprolactinemia (affected by the variable definitions of cure/recurrence, observation periods, and dropout rates) was 18.2\% (4). Studies published during the period covered in this review on patients with microprolactinoma treated with the microscopic transsphenoidal technique and with main indications resistance/intolerance to DAs or patient's choice suggest that biochemical remission with normoprolactinemia is achieved usually in 71-93\% of the cases; serum PRL had been checked shortly after or within the first weeks following surgery $(13,14,15,16$, $17,18,19,20,21,22,23,24$ ) (Table 1). In a large series of 400 patients treated by the sublabial transsphenoidal approach by a single neurosurgeon, postoperative remission was reported in $82 \%$ of the cases; information on previous treatment with DAs was not available (14). Raverot and coworkers in a collaborative multicenter study of 43 patients who stopped the DAs 1 month before the operation found a 93\% remission rate (18). In two series with 46 (20) and 59 (24) patients operated on by two experienced neurosurgeons in a single center, early postoperative normoprolactinemia was reported in 91 and 78\% of the cases respectively; DAs had been stopped before surgery (at least 4 weeks in the first and at least 2 months (in almost half of the patients) in the second study). Mortini and coworkers in a series of 69 patients operated on in a single center by two surgeons (21) showed postoperative remission rate 75\% (off DA for at least 2 months). Lower postoperative remission rates (40-63\%) have been reported in three series with, however, small number of patients $(5,27,32)$ affecting the estimation of the relevant rates $(25,26,27)$. Most studies with mean/median follow-up period ranging between 12 and 84 months suggest that recurrence of the hyperprolactinaemia is observed between 0 and $13 \%$ of the cases $(15,16,17,20,23)$. In one study, however, a recurrence rate of 33\% was described during a median observation period of 33 months (22). It should be noted that information on the timing of stopping DA treatment was not available in this report, and the possibility that the rate of early biochemical remission may also reflect the impact of DA cannot be excluded.

Series reporting the outcomes of endoscopic transsphenoidal surgery in microprolactinomas are rather limited (Table 2). The postoperative remission rates range between 81 and 100\%, and in all but one of the studies, there is no available information on previous DA administration $(19,28,29,30,31,32,33,34,35)$. Given that the main advantages of the endoscopic approach involve invasive adenomas, it would be anticipated that the remission rates should not differ between microscopic and endoscopic techniques in microprolactinomas. The recurrence rate of $0 \%$ has been described in two series with 7 (32) and 12 (34) patients within a median follow-up period of 62 and 15 months respectively. Tanei and coworkers (29) reported the relapse rate of $25 \%$, but this relies on a group of only four patients.

Series confirming that the operations were carried out by one or two surgeons in a single center or by surgeons each performing 80 pituitary operations per year mostly show higher remission rates $(82-100 \%)(13,14,15$, $16,18,20,30,31,32)$ pointing out the importance of surgical expertise. Other factors affecting biochemical remission are not clearly defined specifically for the microprolactinomas as the reported results include analyses for both micro- and macroprolactinomas. Tamasauskas and coworkers (26) suggested that the lack of preoperative therapy with DAs was an independent factor associated with optimal surgical outcome in microprolactinomas; perivascular fibrosis in the adenoma (36) introduced by the medical treatment was a possible mechanism. However, a number of series including both micro- and macroprolactinomas did not confirm this finding $(13,16,24,25)$. The preoperative PRL levels have been negatively associated with remission in all types of prolactinomas $(16,20,24,25,27)$; nonetheless, the impact of previous DA treatment on the PRL values used for the statistical analyses is not clear. Finally, Primeau and coworkers (25) in a series of 63 patients operated on for a prolactinoma (43\% micro-) showed that the absence of adenoma tissue on MRI performed 3 months postoperatively was positively related with remission of the hyperprolactinemia. 
Table 2 Outcomes of series including patients with microprolactinoma treated by the endoscopic transsphenoidal approach (as confirmed by the authors of the papers).

\begin{tabular}{|c|c|c|c|c|c|c|c|}
\hline Reference & $\begin{array}{l}\text { Total } \boldsymbol{N} \text { Age } \\
\text { (years) (range) }\end{array}$ & $\begin{array}{c}\text { Males } \boldsymbol{N} \\
\text { Age (years) }\end{array}$ & $\begin{array}{c}\text { Females } \boldsymbol{N} \\
\text { Age (years) } \\
\text { (range) }\end{array}$ & $\begin{array}{l}\text { Indications for } \\
\text { surgery }\end{array}$ & $\begin{array}{c}\text { Follow-up } \\
\text { (months) (range) }\end{array}$ & $\begin{array}{c}\text { Number of patients } \\
\text { on remission of } \\
\text { hyperprolactinemia } \\
\text { postoperatively (\%) }\end{array}$ & $\begin{array}{c}\text { Number of patients } \\
\text { with recurrence of } \\
\text { hyperprolactinemia } \\
(\%)\end{array}$ \\
\hline (28) & 11 & & - & $\begin{array}{l}\text { DA resistance or } \\
\text { intolerance }\end{array}$ & $-^{a}$ & $10(91 \%)^{a}$ & - \\
\hline (29) & 4 & 0 & $4(18-35)$ & - & Mean $34 \pm 13$ & $4(100 \%)^{b}$ & $1 / 4(25 \%)^{b}$ \\
\hline (30) & 39 Mean $29 \pm 9$ & & - & $\begin{array}{l}\text { DA resistance or } \\
\text { intolerance } \\
\text { Cystic adenoma } \\
\text { Patient's } \\
\text { preference }\end{array}$ & - & $39(100 \%)^{c}$ & - \\
\hline$(31)^{d}$ & 13 Mean $37 \pm 3^{e}$ & & - & $\begin{array}{l}\text { DA resistance or } \\
\text { intolerance }\end{array}$ & Mean $22 \pm 3^{e}$ & $12(92 \%)$ & - \\
\hline (32) & 7 & & - & $\begin{array}{l}\text { DA resistance or } \\
\text { intolerance } \\
\text { Patient's } \\
\text { preference }\end{array}$ & $\begin{array}{c}\text { Median } 62 \\
(8-132)^{f}\end{array}$ & $7(100 \%)$ & $0 / 7(0 \%)$ \\
\hline (19) & 16 & & - & - & $\begin{array}{l}\text { Mean } 18 \\
(1-76)^{f}\end{array}$ & $13(81 \%)^{g}$ & - \\
\hline$(33)^{\mathrm{h}}$ & 17 & & - & - & - & $16(94)^{\mathrm{h}}$ & \\
\hline$(34)^{i}$ & 12 & & - & $\begin{array}{l}\text { DA resistance or } \\
\text { intolerance }\end{array}$ & $\begin{array}{l}\text { Median } 15 \\
(4-31)^{\mathrm{e}}\end{array}$ & $12(100 \%)^{i}$ & $0 / 12(0 \%)$ \\
\hline$(35)^{j}$ & $\begin{array}{l}28 \text { Mean } 36 \\
(7-82)^{\mathrm{e}}\end{array}$ & & - & - & $\begin{array}{l}\text { Median } 54 \\
(19-54)^{f}\end{array}$ & $24(86 \%)^{j}$ & - \\
\hline
\end{tabular}

${ }^{a}$ Follow-up data specifically for microprolactinomas are not reported. Remission was defined as normal PRL off DA in the last follow-up appointment. ${ }^{b}$ Remission was defined as normal PRL 3 months postoperatively. The recurrence in one patient was detected 16 months postoperatively.

'Remission was defined as normoprolactinemia on the seventh postoperative day. Information on previous treatment with DAs and timing of stopping is not available.

${ }^{\mathrm{d}}$ The study included 35 patients with prolactinoma (13 with micro- and 22 with macroprolactinoma). Eight patients had been previously operated, but it is not clarified if among them there were ones with microprolactinoma. Information of timing of stopping the DA prior to surgery is not available.

'Data for both micro- and macroprolactinomas are reported.

fData for all pituitary tumours are included in this series. Information on previous treatment with DAs and timing of stopping it is not available. gRemission was defined as normalization of PRL checked at least 6 weeks postoperatively and after withdrawal of DA during the same period.

hThe series included 194 patients with 77 functioning and 131 nonfunctioning pituitary adenomas. Thirty tumours were operated on after recurrence; there is no information if microprolactinomas were included in this group. PRL was checked intraoperatively. Information on previous treatment with DAs and timing of stopping is not available.

'The study included 25 patients with prolactinoma (12 with micro- and 13 patients with macroprolactinoma). One of them had undergone prior microscopic transsphenoidal surgery but it was not clarified if this patient had a micro- or a macroprolactinoma. Remission was defined as normal PRL the day after surgery. Information on previous treatment with DAs and timing of stopping it is not available.

iThe series included 418 patients with pituitary adenomas, 79 of whom were operated after tumour recurrence; there was no information if microprolactinomas were included in this group. Remission was defined as normal PRL levels at the latest check and off DA for at least 2 months.

The main drawbacks of the published literature include the small number of patients and the short observation period in many series (particularly the endoscopic ones), as well as the variable protocols for the confirmation of biochemical remission and detection of recurrence (timing of blood sampling after surgery, duration of stopping DAs). Furthermore, the specific indications for surgery may have introduced a bias in the selection of patients studied; the impact of this (positive or negative) in the reported outcomes is not clear. Finally, the available literature may not necessarily reflect the 'real-life' outcomes, as the published data tend to represent the experience of large centers with usually optimal results.

\section{Peri- and post-operative complications in microprolactinomas}

The reported peri- and postoperative complications in microscopic series include mortality $0 \%(13,15,16$, $17,19,20,21,22,24,27)$, visual deterioration $0 \%(13$, $15,27)$, and other neurosurgical complications $0-1.8 \%$ 
(febrile sinusitis, epistaxis requiring emergency nasal tamponade, and mucocele requiring evacuation 1 year later) $(20,24)$. The outcomes of pituitary function are given in Table 3 , and in all $(15,19,20,22,24,26)$ but one (with a very small number of patients) (23) studies, they look rather optimal; hypogonadism or permanent diabetes insipidus was found between 0 and $6 \%$.

The reported peri- and postoperative complications in endoscopic series include mortality $0 \%(19,29,30,31$, $33,34,35,37)$, visual deterioration $0 \%(32,34,37)$, and other neurosurgical complications $0 \%$ (37). The outcomes of pituitary function are given in Table 3; new pituitary hormone deficits range between 0 and $6 \%(19,29,30,37)$. Notably, no cases of permanent diabetes insipidus have been described.

\section{Quality of life and costs}

Data on the quality of life of patients with microprolactinomas treated by surgery are not currently available. Based on a study from the UK published in 1999 (38), the costs for a hypothetical patient with microprolactinoma undergoing surgery and cure with no complications and followed up for 10 years did not differ from those required for a patient receiving cabergoline $1 \mathrm{mg} /$ week for 10 years.

In a very recently published study (39) Jethwa and coworkers performed a cost-effectiveness analysis comparing transsphenoidal surgery (microscopic or endoscopic) and medical therapy (bromocriptine or cabergoline) in microprolactinomas using decision analysis modeling. Each probability (cure rates, complications) in the model was based on data gathered from the published literature, and costs were taken from the perspective of the US health-care third-party payer. Base case analysis revealed that medical therapy was more costly and less effective than surgery in young patients with life expectancy greater than 10 years. The authors propose that the costs of medications continue to accumulate with time, whereas the costs of surgery are realized upfront and do not recur on a continuous basis, unless the patient has postoperative hypopituitarism requiring hormone replacement therapy. They point out though that the operation should be performed only by experienced surgeons at high volume centers with optimal biochemical cure and low complications rates. It should be noted, however, that in this study a number of assumptions had to be made in order to complete the model; these may not be a perfect reflection of the real world, thereby introducing errors, and
Table 3 Pituitary function after transsphenoidal surgery for microprolactinomas.

\begin{tabular}{|c|c|c|c|}
\hline Reference & $n$ & $\begin{array}{l}\text { Anterior pituitary hormone } \\
\text { deficits }\end{array}$ & $\begin{array}{c}\text { Posterior pituitary } \\
\text { dysfunction }\end{array}$ \\
\hline \multicolumn{4}{|c|}{ Microscopic series } \\
\hline$(26)$ & 32 & - & $\begin{array}{l}5 / 32(16 \%) \\
\text { Transient DI } \\
2 / 32(6 \%) \\
\text { Permanent DI }\end{array}$ \\
\hline (15) & 24 & $\begin{array}{c}1 / 24(4 \%)^{a} \\
\text { Hypogonadotropic } \\
\text { hypogonadism }\end{array}$ & $\begin{array}{c}1 / 24(4 \%)^{b} \\
\text { Transient SIADH }\end{array}$ \\
\hline (19) & 21 & $0(0 \%)$ & - \\
\hline (20) & 56 & $0(0 \%)$ & - \\
\hline (22) & 20 & $0(0 \%)$ & - \\
\hline (23) & 11 & $\begin{array}{l}\qquad 5 / 11(46 \%)^{c} \\
\text { Hypogonadotropic } \\
\text { hypogonadism } \\
\text { (testosterone deficiency) } \\
\quad 1 / 11(9 \%)^{d} \\
\text { Central hypothyroidism }\end{array}$ & $\begin{array}{l}2 / 11(18 \%) \\
\text { Transient DI }\end{array}$ \\
\hline (24) & 59 & $0(0 \%)$ & - \\
\hline \multicolumn{4}{|c|}{ Endoscopic series } \\
\hline $\begin{array}{l}(29) \\
(37)\end{array}$ & $\begin{array}{r}4 \\
16\end{array}$ & $\begin{array}{l}0(0 \%) \\
1 / 16(6 \%) \\
\text { ACTH and reported TSH } \\
\text { deficiency (diagnosed on } \\
\text { seventh postoperative } \\
\text { day) }\end{array}$ & - \\
\hline (30) & 39 & $0(0 \%)^{\mathrm{e}}$ & $\begin{array}{c}1 / 39(3 \%) \\
\text { Transient DI }\end{array}$ \\
\hline (19) & 16 & $0(0 \%)$ & - \\
\hline
\end{tabular}

aPermanent hypogonadotropic hypogonadism despite postoperative normal PRL levels.

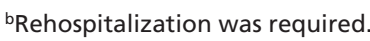

cPostoperatively, five patients were testosterone deficient (central hypogonadism) despite being normoprolactinemic (three after surgery alone and two on additional DA therapy).

dPostoperatively, central hypothyroidism was reported in one patient but preoperative assessment was not available.

eNo permanent adrenal insufficiency was reported. Adrenal function recovered 6 months after surgery in 29 patients and 18 months after surgery in the remaining ones.

may not necessarily apply to different medical economic environments in other countries.

\section{Conclusions and future perspectives}

In the past few decades, medical treatment has been considered the mainstay in the management of microprolactionomas. This relies on the wellestablished high biochemical control and low drug intolerance rates (particularly for cabergoline, 85-93 and $4 \%$, respectively) leading physicians to overlook 
the option of surgical removal and often not to discuss this with the patient at the time of diagnosis. Based on the literature published in the past 15 years and keeping in mind its limitations as described previously, surgery by experienced hands can achieve biochemical control in $82-100 \%$ of the cases with practically minimum complication rates; among them, permanent diabetes insipidus (up to 6\%) is probably the one requiring more attention. The reported recurrence rates (derived mostly from microscopical transsphenoidal operations) need to be taken into account, although at present, they do not seem to be particularly high (mostly $0-13 \%)$.

Therefore, in centers with neurosurgical expertise in which the chance of successful and safe removal of a symptomatic microprolactinoma can be high, the adoption of this route is not an unreasonable approach and needs at least to be discussed with the patient or even offered as primary therapy to selected, suitable patients. This is of particular relevance for young patients with a favorable surgical target who may require decades of medical therapy or for those noncompliant to DA treatment (provided surgery is not complicated by hypopituitarism requiring replacement).

Areas that need to be further clarified in this field include the impact of longer observation periods on sustaining biochemical remission and the timing of recurrence (if detected long after the operation allowing a female to reach menopause, it may not be of clinical significance). Such data should be generated from large series of nonselected (if possible) patients followed up by robust protocols. Also, quality of life, financial strains on patients, and their families and cost-effectiveness issues remain to be elucidated. Finally, further outcomes of endoscopic surgery in microprolactinomas are eagerly awaited.

\section{Declaration of interest}

The authors declare that there is no conflict of interest that could be perceived as prejudicing the impartiality of the data reported.

\section{Funding}

Dr Metaxia Tampourlou has been rewarded a fellowship grant from the Hellenic Endocrine Society.

\section{References}

1 Karavitaki N. Prevalence and incidence of pituitary adenomas. Annales d'Endocrinologie 201273 79-80. (doi:10.1016/j. ando.2012.03.039)
2 Fernandez A, Karavitaki N \& Wass JA. Prevalence of pituitary adenomas: a community-based, cross-sectional study in Banbury (Oxfordshire, UK). Clinical Endocrinology 201072 377-382. (doi:10.1111/cen.2010.72.issue-3)

3 Melmed S, Casanueva FF, Hoffman AR, Kleinberg DL, Montori VM, Schlechte JA, Wass JA \& Endocrine Society. Diagnosis and treatment of hyperprolactinemia: an Endocrine Society clinical practice guideline. Journal of Clinical Endocrinology and Metabolism 201196 273-288. (doi:10.1210/jc.2010-1692)

4 Gillam MP, Molitch ME, Lombardi G \& Colao A. Advances in the treatment of prolactinomas. Endocrine Reviews 200627 485-534. (doi:10.1210/er.2005-9998)

5 Di Sarno A, Landi ML, Cappabianca P, Di Salle F, Rossi FW, Pivonello R, Di Somma C, Faggiano A, Lombardi G \& Colao A. Resistance to cabergoline as compared with bromocriptine in hyperprolactinemia: prevalence, clinical definition, and therapeutic strategy. Journal of Clinical Endocrinology and Metabolism 200186 5256-5261.

6 Webster J, Piscitelli G, Polli A, Ferrari CI, Ismail I \& Scanlon MF. A comparison of cabergoline and bromocriptine in the treatment of hyperprolactinemic amenorrhea. Cabergoline Comparative Study Group. New England Journal of Medicine 1994331 904-909. (doi:10.1056/NEJM199410063311403)

7 Verhelst J, Abs R, Maiter D, van den Bruel A, Vandeweghe M, Velkeniers B, Mockel J, Lamberigts G, Petrossians P, Coremans P et al. Cabergoline in the treatment of hyperprolactinemia: a study in 455 patients. Journal of Clinical Endocrinology and Metabolism 199984 2518-2522. (doi:10.1210/jcem.84.7.5810)

8 Webster J, Piscitelli G, Polli A, D'Alberton A, Falsetti L, Ferrari C, Fioretti P, Giordano G, L'Hermite M, Ciccarelli E et al. (European multicentre cabergoline study group). The efficacy and tolerability of long-term cabergoline therapy in hyperprolactinaemic disorders: an open, uncontrolled, multicentre study. European Multicentre Cabergoline Study Group. Clinical Endocrinology 199339 323-329. (doi:10.1111/j.1365-2265.1993.tb02372.x)

9 Dekkers OM, Lagro J, Burman P, Jørgensen JO, Romijn JA \& Pereira AM. Recurrence of hyperprolactinemia after withdrawal of dopamine agonists: systematic review and meta-analysis. Journal of Clinical Endocrinology and Metabolism 201095 43-51. (doi:10.1210/ jc.2009-1238)

10 Huda MS, Athauda NB, Teh MM, Carroll PV \& Powrie JK. Factors determining the remission of microprolactinomas after dopamine agonist withdrawal. Clinical Endocrinology 201072 507-511. (doi:10.1111/j.1365-2265.2009.03657.x)

11 Noronha S, Stokes V, Karavitaki N \& Grossman A. Treating prolactinomas with dopamine agonists: always worth the gamble? Endocrine 201551 205-210. (doi:10.1007/s12020-015-0727-2)

12 Drake WM, Stiles CE, Howlett TA, Toogood AA, Bevan JS, Steeds RP \& UK Dopamine Agonist Valvulopathy Group. A cross-sectional study of the prevalence of cardiac valvular abnormalities in hyperprolactinemic patients treated with ergot-derived dopamine agonists. Journal of Clinical Endocrinology and Metabolism 201499 90-96. (doi:10.1210/jc.2013-2254)

13 Ikeda H, Watanabe K, Tominaga T \& Yoshimoto T. Transsphenoidal microsurgical results of female patients with prolactinomas. Clinical Neurology and Neurosurgery 2013115 1621-1625. (doi:10.1016/j. clineuro.2013.02.016)

14 Loyo-Varela M, Herrada-Pineda T, Revilla-Pacheco F \& ManriqueGuzman S. Pituitary tumor surgery: review of 3004 cases. World Neurosurgery 201379 331-336. (doi:10.1016/j.wneu.2012.06.024)

15 Babey M, Sahli R, Vajtai I, Andres RH \& Seiler RW. Pituitary surgery for small prolactinomas as an alternative to treatment with dopamine agonists. Pituitary 201114 222-230. (doi:10.1007/s11102-010-0283-y)

16 Qu X, Wang M, Wang G, Han T, Mou C, Han L, Jiang M, Qu Y, Zhang M, Pang Q et al. Surgical outcomes and prognostic factors of transsphenoidal surgery for prolactinoma in men: a single-center 
experience with 87 consecutive cases. European Journal of Endocrinology 2011164 499-504. (doi:10.1530/EJE-10-0961)

17 Sinha S, Sharma BS \& Mahapatra AK. Microsurgical management of prolactinomas - clinical and hormonal outcome in a series of 172 cases. Neurology India 201159 532-536.

18 Raverot G, Wierinckx A, Dantony E, Auger C, Chapas G, Villeneuve L, Brue T, Figarella-Branger D, Roy P, Jouanneau E et al. $\&$ HYPOPRONOS. Prognostic factors in prolactin pituitary tumors: clinical, histological, and molecular data from a series of 94 patients with a long postoperative follow-up. Journal of Clinical Endocrinology and Metabolism 201095 1708-1716. (doi:10.1210/jc.2009-1191)

19 D'Haens J, Van Rompaey K, Stadnik T, Haentjens P, Poppe K \& Velkeniers B. Fully endoscopic transsphenoidal surgery for functioning pituitary adenomas: a retrospective comparison with traditional transsphenoidal microsurgery in the same institution. Surgical Neurology 200972 336-340. (doi:10.1016/j. surneu.2009.04.012)

20 Kreutzer J, Buslei R, Wallaschofski H, Hofmann B, Nimsky C, Fahlbusch R \& Buchfelder M. Operative treatment of prolactinomas: indications and results in a current consecutive series of 212 patients. European Journal of Endocrinology 2008158 11-18. (doi:10.1530/EJE07-0248)

21 Mortini P, Losa M, Barzaghi R, Boari N \& Giovanelli M. Results of transsphenoidal surgery in a large series of patients with pituitary adenoma. Neurosurgery 200556 1222-1233.

22 Esposito V, Santoro A, Minniti G, Salvati M, Innocenzi G, Lanzetta G \& Cantore G. Transsphenoidal adenomectomy for GH-, PRL- and ACTH-secreting pituitary tumours: outcome analysis in a series of 125 patients. Neurological Sciences 200425 251-256. (doi:10.1007/s10072004-0351-z)

23 Wolfsberger S, Czech T, Vierhapper H, Benavente R \& Knosp E. Microprolactinomas in males treated by transsphenoidal surgery. Acta Neurochirurgica 2003145 935-940. (doi:10.1007/s00701-0030134-y)

24 Losa M, Mortini P, Barzaghi R, Gioia L \& Giovanelli M. Surgical treatment of prolactin-secreting pituitary adenomas: early results and long-term outcome. Journal of Clinical Endocrinology and Metabolism $2002873180-3186$.

25 Primeau V, Raftopoulos C \& Maiter D. Outcomes of transsphenoidal surgery in prolactinomas: improvement of hormonal control in dopamine agonist-resistant patients. European Journal of Endocrinology 2012166 779-786. (doi:10.1530/EJE-11-1000)

26 Tamasauskas A, Sinkunas K, Bunevicius A, Radziunas A, Skiriute D \& Deltuva VP. Transsphenoidal surgery for microprolactinomas in women: results and prognosis. Acta Neurochirurgica 2012154 1889-1893. (doi:10.1007/s00701-012-1450-x)

27 Kristof RA, Schramm J, Redel L, Neuloh G, Wichers M \& Klingmüller D. Endocrinological outcome following first time transsphenoidal surgery for GH-, ACTH-, and PRL-secreting pituitary adenomas. Acta Neurochirurgica 2002144 555-561. (doi:10.1007/ s00701-002-0938-1)
28 Paluzzi A, Fernandez-Miranda JC, Tonya Stefko S, Challinor S, Snyderman CH \& Gardner PA. Endoscopic endonasal approach for pituitary adenomas: a series of 555 patients. Pituitary $2014 \mathbf{1 7}$ 307-319. (doi:10.1007/s11102-013-0502-4)

29 Tanei T, Nagatani T, Nakahara N, Watanabe T, Nishihata T, Nielsen ML, Takebayashi S, Hirano M \& Wakabayashi T. Use of high-field intraoperative magnetic resonance imaging during endoscopic transsphenoidal surgery for functioning pituitary microadenomas and small adenomas located in the intrasellar region. Neurologia medico-chirurgica 201353 501-510. (doi:10.2176/ nmc.53.501)

30 Marić A, Kruljac I, Čerina V, Pećina HI, Šulentić P \& Vrkljan M. Endocrinological outcomes of pure endoscopic transsphenoidal surgery: a Croatian Referral Pituitary Center experience. Croatian Medical Journal 201253 224-233. (doi:10.3325/ cmj.2012.53.224)

31 Hofstetter CP, Shin BJ, Mubita L, Huang C, Anand VK, Boockvar JA \& Schwartz TH. Endoscopic endonasal transsphenoidal surgery for functional pituitary adenomas. Neurosurgical Focus 201130 E10.

32 Gondim JA, Schops M, de Almeida JP, de Albuquerque LA, Gomes E, Ferraz T \& Barroso FA. Endoscopic endonasal transsphenoidal surgery: surgical results of 228 pituitary adenomas treated in a pituitary center. Pituitary 201013 68-77. (doi:10.1007/s11102-009-0195-x)

33 Yano S, Kawano T, Kudo M, Makino K, Nakamura H, Kai Y, Morioka M $\&$ Kuratsu J. Endoscopic endonasal transsphenoidal approach through the bilateral nostrils for pituitary adenomas. Neurologia medico-chirurgica 200949 1-7. (doi:10.2176/nmc.49.1)

34 Dehdashti AR, Ganna A, Karabatsou K \& Gentili F. Pure endoscopic endonasal approach for pituitary adenomas: early surgical results in 200 patients and comparison with previous microsurgical series. Neurosurgery 200862 1006-1017. (doi:10.1227/01. neu.0000325862.83961.12)

35 Frank G, Pasquini E, Farneti G, Mazzatenta D, Sciarretta V, Grasso V \& Faustini Fustini M. The endoscopic versus the traditional approach in pituitary surgery. Neuroendocrinology $200683240-248$.

36 Landolt AM, Keller PJ, Froesch ER \& Mueller J. Bromocriptine: does it jeopardise the result of later surgery for prolactinomas? Lancet 19822 657-658.

37 Berker M, Hazer DB, Yücel T, Gürlek A, Cila A, Aldur M \& Onerci M. Complications of endoscopic surgery of the pituitary adenomas: analysis of 570 patients and review of the literature. Pituitary $2012 \mathbf{1 5}$ 288-300. (doi:10.1007/s11102-011-0368-2)

38 Turner HE, Adams CB \& Wass JA. Trans-sphenoidal surgery for microprolactinoma: an acceptable alternative to dopamine agonists? European Journal of Endocrinology 1999140 43-47. (doi:10.1530/ eje.0.1400043)

39 Jethwa PR, Patel TD, Hajart AF, Eloy JA, Couldwell WT \& Liu JK. Cost-effectiveness analysis of microscopic and endoscopic transsphenoidal surgery versus medical therapy in the management of microprolactinoma in the United States. World Neurosurgery 2016 87 65-76. (doi:10.1016/j.wneu.2015.10.090)

Received 31 January 2016

Revised version received 9 March 2016

Accepted 11 March 2016 